\title{
ENTRE O MATERIAL DIDÁTICO E A PROMESSA: 0 DISCURSO ACERCA DAS NOVAS TECNOLOGIAS NA TEORIZAÇÃO SOBRE O ENSINO E A APRENDIZAGEM DE LÍNGUAS ESTRANGEIRAS
}

\author{
BETWEEN PEDAGOGICAL INSTRUMENT AND PROMISE \\ - THE DISCOURSE UPON NEW TECHNOLOGIES IN THE \\ THEORIZATION ABOUT FOREIGN LANGUAGE TEACHING \\ AND LEARNING
}

\section{Edmundo Narracci Gasparini ${ }^{*}$}

\section{RESUMO}

$\mathrm{O}$ artigo apresenta parte de uma pesquisa que investigou o discurso acerca das novas tecnologias na teorização sobre o ensino e a aprendizagem de línguas estrangeiras. $\mathrm{Na}$ pesquisa, foram analisados artigos científicos publicados em um periódico online do campo da Linguística Aplicada. Os resultados da análise aqui apresentada indicam que o discurso investigado se constitui na relação com dois outros discursos, quais sejam, o discurso do material didático e o discurso da tecnologia em si. O recorte aqui apresentado indica que é entre a condição de material didático utilizado por professores e alunos e a de garantia de aprendizagem bem-sucedida que as novas tecnologias se constituem no âmbito da teorização sobre o ensino e a aprendizagem de línguas estrangeiras. No jogo interdiscursivo aqui delineado, o ponto em que as novas tecnologias nos subjetivam, uma vez que fazem parte de uma engrenagem de poder constitutiva do mundo contemporâneo, é objeto de um silenciamento.

Palavras-chave: discurso; novas tecnologias; ensino e aprendizagem de línguas estrangeiras.

\section{ABSTRACT}

This article presents part of a research which investigated the discourse upon new technologies in the theorization about foreign language teaching and learning. The research aimed at investigating the discourse upon new technologies in theorization, and papers published in an online journal of Applied Linguistics were analysed. The results presented here indicate that the discourse which was investigated is constituted in relation to two other discourses: the discourse of pedagogical instruments and the discourse of technology itself. According to the analysis presented here, it is between pedagogical instrument used by teachers and students and guarantee of successful learning that new technologies are constituted in the theorization about foreign language teaching and learning. In the

\footnotetext{
* Universidade Federal de São João del-Rei (UFSJ), São João del-Rei, MG, Brasil. gaspar@ufsj.edu.br, https://orcid.org/0000-0001-7067-7277
} 
interdiscursive relations delineated here, the point in which new technologies subjectivize us, once they are part of power relations in the contemporary world, is silenced. Keywords: discourse; new technologies; foreign language teaching and learning.

\section{CONSIDERAÇÕES INICIAIS}

O presente artigo tem como objetivo apresentar parte da pesquisa "O discurso acerca das novas tecnologias na teorização sobre o ensino e a aprendizagem de línguas estrangeiras", desenvolvida em 2017-2018 no Instituto de Estudos da Linguagem, UNICAMP ${ }^{1}$. A investigação se propôs a responder à seguinte pergunta: como se configura, em suas relações interdiscursivas, o discurso acerca das novas tecnologias na teorização sobre o ensino e a aprendizagem de línguas estrangeiras? Para abordar esta questão, propusemo-nos a analisar artigos científicos publicados em um periódico online do campo da Linguística Aplicada, campo em que se situa a teorização sobre o ensino e a aprendizagem de línguas.

De início, importa mencionar aqui o conceito de novas tecnologias assim como proposto por Cunha e Souza (2009):

Tendemos a associar novas tecnologias ao conceito de Novas Tecnologias da Informação e Comunicação (doravante NTIC), o qual se refere aos métodos e tecnologias que surgiram com a Revolução Informacional com o intuito de comunicação, principalmente a partir da década de 1990. (CUNHA; SOUZA, 2009, p. 85)

Cunha e Souza acrescentam que tais tecnologias, em sua maioria, articulamse à digitalização de informações (na forma de texto, imagem, vídeo ou som) e sua transmissão em redes. Os autores trazem também a contribuição de Belloni, considerada "uma definição apropriada de NTIC" (CUNHA; SOUZA, 2009, p. 86):

Correndo o risco de simplificar, podemos dizer que, nos tempos que correm, as NTICs são fundamentalmente aquelas - recheadas de informática - que permitem a estocagem e a transmissão de informações em quantidade, qualidade e velocidade inéditas na história da humanidade e que têm como característica essencial a "imaterialidade" de sua matéria-prima, a informação. (BELLONI apud CUNHA; SOUZA, 2009, p. 86)

Importante na tentativa de delimitação feita por Cunha e Souza (2009) é a ideia de que as novas tecnologias referem-se à transmissão de informações digitalizadas (em quantidade, qualidade e velocidade inéditas na história). A

1. Pesquisa desenvolvida em estágio pós-doutoral sob orientação do professor Lauro José Siqueira Baldini. 
esse respeito, talvez não seja sem relevância lembrar que, no final dos anos 60, Michel Pêcheux aborda o discurso afirmando justamente que tal instância da linguagem não se refere a uma transmissão de informações, mas sim a efeitos de sentido entre locutores (PÊCHEUX, 1997) - a perspectiva de uma "comunicação de informações" desponta, a partir de Pêcheux, como uma evidência ideológica. Poderíamos, portanto, perguntar: o que pode ficar elidido sob a evidência de uma "transmissão de informações" associada às novas tecnologias?

Passemos aos elementos teóricos que fundamentaram a análise aqui apresentada.

\section{ELEMENTOS TEÓRICOS}

Em Problemas de Linguística Geral I, Benveniste indica que o problema que persegue a Linguística moderna refere-se à relação forma-sentido. Segundo o autor, são inúteis as tentativas de evitar, ignorar ou expulsar o sentido: "essa cabeça de Medusa está sempre aí, no centro da língua, fascinando os que a contemplam" (BENVENISTE, 2005, p. 135). A Análise do Discurso forjada por Michel Pêcheux a partir do final dos anos 60 se configura como uma abordagem do problema mencionado por Benveniste, como uma forma de lidar com a questão do sentido em sua condição de elemento que, como cabeça de Medusa, causa fascínio mas também horror. Abandonada com a instauração do corte saussuriano, a questão da significação de textos insistia em se fazer ouvir, como indica Pêcheux em Análise Automática do Discurso. A Análise de Discurso forjada então é uma tentativa de abordar uma questão que, abandonada, continuou a se colocar. Tratou-se, entretanto, de uma abordagem da questão do sentido que instaurou como elemento central a determinação bistórica dos processos de significação (ORLANDI, 1996, p. 12, destaque da autora).

O discurso é, portanto, espaço de constituição, reprodução e transformação dos sentidos na história. Já em 1969, Pêcheux o define como efeito de sentidos entre locutores (PÊCHEUX, 1997). A questão do endereçamento é, para Pêcheux, fundamental, visto é que no endereçamento ao outro - isto é, entre locutores que advêm os efeitos de sentido. Trata-se, contudo, de pensar em locutores que, mais que indivíduos, configuram-se como sujeitos. Vale lembrar a indicação de Althusser (1998), fundamental para Pêcheux, segundo a qual a ideologia interpela o indivíduo em sujeito. Trata-se, portanto, de um locutor que fala - a um outro - na ilusão de que controla o seu dizer, na ilusão da "comunicação", mas que desconhece aquilo que o determina. Não é sem importância que Althusser, ao propor sua teoria 
da ideologia em geral, aproxime ideologia de inconsciente: a ideologia é eterna, como o inconsciente (ALTHUSSER, 1998). Como o inconsciente, a ideologia, na condição de a-histórica (isto é, apresentando uma estrutura e um funcionamento imutáveis ao longo da história), exerce seus efeitos de determinação no dizer, ao mesmo tempo em que engendra a ilusão do sujeito causa-de-si, dono de seu dizer. Como não lembrar aqui da indicação de Jacques Lacan (1986, p. 67) segundo a qual a função fundamental do Eu é o desconhecimento?

Os conceitos de processo discursivo e formação discursiva revestem-se de importância para a pesquisa aqui apresentada. Já em Análise Automática do Discurso, Pêcheux refere-se ao efeito metafórico afirmando que "esse 'deslizamento de sentido' entre $x$ e $y$ é constitutivo do 'sentido' designado por $x$ e $y^{\prime \prime}$ (PÊCHEUX, 1997, p. 96). É nesta perspectiva que o autor refere-se ao processo de produção de um discurso - isto é, o processo discursivo - como "um tecido de elementos solidários, instalando-se e assegurando-se a si mesmo através de efeitos metafóricos" (PÊCHEUX, 1997, p. 97).

Em Semântica e Discurso, Pêcheux afirma que o processo discursivo designa "o sistema de relações de substituição, paráfrase, sinonímias, etc., que funcionam entre elementos linguísticos - 'significantes' - em uma formação discursiva dada" (PÊCHEUX, 1988, p. 161). Importa destacar que a formação discursiva comparece na afirmação de Pêcheux como lugar em que se desdobram os efeitos de sentido engendrados pelo processo discursivo. A partir das indicações de Pêcheux, vislumbramos a possibilidade de delimitar os contornos de uma formação discursiva em que funcionam relações significantes constitutivas de efeitos de sentido acerca das novas tecnologias na teorização sobre o ensino e a aprendizagem de línguas, formação na qual se configura o que pode e deve ser dito acerca das novas tecnologias.

Entretanto, se por um lado uma formação discursiva determina o que pode e deve ser dito (PÊCHEUX, 1988 e PÊCHEUX; HAROCHE; HERNY, 1990), funcionando como "um princípio de aceitabilidade discursiva" (COURTINE, 2014, p. 99), ela é também "um princípio de exclusão (determina 'o que não pode / não deve ser dito')" (COURTINE, 2014, p. 99). A indicação de Courtine acerca de um princípio de exclusão leva, portanto, à consideração do que, numa formação discursiva, tende a ser silenciado (cf. ORLANDI, 1997). Ponto fundamental da pesquisa realizada, como teremos a oportunidade de vislumbrar.

Não é sem relevância recorrer ao conceito de interdiscurso assim como forjado por Pêcheux em Semântica e Discurso. Com tal conceito, Pêcheux faz incidir na teoria o fato de que um discurso remete necessariamente a outro; uma formação 
discursiva - espaço de constituição do sentido e que determina o dizer a partir de uma posição numa conjuntura social (PÊCHEUX, 1988 e PÊCHEUX; HAROCHE; HERNY, 1990) - está sempre relacionada a outras formações discursivas. É nessa perspectiva que o interdiscurso remete ao "todo complexo com dominante' das formações discursivas" (PÊCHEUX, 1988, p. 162). "Todo" não no sentido de um elemento totalizável, mas de um universo complexo no qual há uma heterogeneidade de sentidos.

Ganham relevância aqui as indicações de Courtine (2014) sobre as relações contraditórias que uma formação discursiva (FD) estabelece com outras, relações que se inscrevem na própria materialidade linguística dessa $\mathrm{FD}$, afetada que é pelo interdiscurso. Se uma FD determina o que pode e deve ser dito, tal característica não se encontra isolada das relações contraditórias que ela estabelece com outras FD's. Trata-se de colocar em destaque que uma FD é afetada pelo que lhe é exterior, configurando-se portanto como espaço de heterogeneidade:

Se uma dada FD não é isolável das relações de desigualdade, de contradição ou de subordinação que marcam sua dependência em relação ao "todo complexo com dominante" [...] das FD, intrincado no complexo da instância ideológica, e se nomeamos "interdiscurso" esse todo complexo com dominantes das FD, então é preciso admitir que o estudo de um processo discursivo no interior de uma dada FD não é dissociável do estudo da determinação desse processo discursivo por seu interdiscurso (COURTINE, 2014, p. 73, destaques do autor)

Importa dizer que a formação discursiva é espaço de subjetivação, espaço em que o indivíduo é interpelado em sujeito. Vale lembrar novamente da indicação de Althusser de acordo com a qual o efeito característica da ideologia é a criação de evidências, e da aproximação realizada pelo filósofo entre a evidência do sujeito - que, interpelado, desconhece sua determinação - e a evidência do sentido, que faz com que "uma palavra 'designe uma coisa' ou 'possua um significado'" (ALHTUSSER, 1998, p. 94). É portanto no espaço de uma formação discursiva que se estabelece uma simultaneidade entre sujeito afetado pela ilusão de autonomia e a ilusão de transparência da linguagem. Se é na formação discursiva que se configuram efeitos de sentido entre locutores, importa dizer que o sentido aí desponta como evidência para locutores interpelados, que desconhecem o seu assujeitamento.

É nessa direção que compreendemos a indicação de Pêcheux (1988) segundo a qual no espaço de uma formação discursiva se constitui uma transparência de sentido - articulada, acrescentamos, a uma "transparência do sujeito" (pois o assujeitamento exerce seus efeitos engendrando a ilusão de autonomia) - que dissimula sua dependência em relação ao interdiscurso. Na análise a ser apresentada aqui, propusemo-nos a atravessar os efeitos de evidência que se estabelecem em 
torno do discurso acerca das novas tecnologias (na teorização sobre o ensino e a aprendizagem de línguas estrangeiras) delineando a configuração interdiscursiva que constitui tal discurso, mostrando os efeitos do "todo complexo com dominante" que aí se exercem.

$\mathrm{Na}$ análise aqui apresentada, o trabalho se deu na direção de delimitar o contorno tênue de uma formação discursiva que, em suas relações contraditórias com outros discursos, estabelece não apenas o que pode e deve ser dito sobre as novas tecnologias, mas também o que não pode e não deve ser dito, isto é, o que fica silenciado (cf. ORLANDI, 1997) no discurso acerca das novas tecnologias na teorização sobre o ensino e a aprendizagem de línguas estrangeiras.

$\mathrm{Na}$ próxima seção, esboçaremos os procedimentos metodológicos que orientaram a análise.

\section{CONSIDERAÇÕES DE ORDEM METODOLÓGICA}

Para realizar a pesquisa, inicialmente planejamos abordar artigos publicados num período de 10 anos (de 2007 até 2016) em 8 periódicos (disponibilizados na Internet) que publicavam trabalhos no campo da Linguística Aplicada. A opção pelas versões online das revistas deu-se em função da facilidade de acessar os artigos disponibilizados na Internet. Por sua vez, optar por artigos possibilitaria, em função da sucintez característica do gênero, abordar um universo mais amplo da pesquisa e da teorização sobre as novas tecnologias no trabalho com línguas estrangeiras.

Feita a seleção inicial, o material de análise constituiu-se por um total de 112 artigos, selecionados a partir de um olhar inicial a seu título e ao resumo, o que permitiu identificar a presença do tema em questão - as novas tecnologias no trabalho com línguas estrangeiras. Após a análise preliminar dos 112 artigos selecionados, decidiu-se reduzir o material de análise para 20 artigos de um único periódico online da área, o Horizontes de Linguística Aplicada ${ }^{2}$. Tal redução fez-se necessária em função da grande quantidade de dados obtidos, cujo tratamento demandaria um tempo maior do que a pesquisa dispunha. A análise preliminar levou-nos a supor que a abordagem dos 20 artigos do periódico Horizontes permitiria analisar satisfatoriamente o discurso acerca das novas tecnologias na teorização sobre o ensino e a aprendizagem de

2. A revista Horizontes de Linguística Aplicada, fundada em 2002, é mantida pelo Programa de PósGraduação em Linguística Aplicada do Departamento de Línguas Estrangeiras e Tradução da Universidade de Brasília. Com publicação semestral, o periódico publica textos inéditos na área de ensino e aprendizagem de línguas. 
línguas estrangeiras, uma vez tais artigos pareceram-nos representativos do que vislumbramos na análise preliminar.

Em oposição aos corpora experimentais, isto é, produzidos a partir de pesquisas empíricas (através de questionários, por exemplo), nosso corpus foi constituído a partir de material preexistente, isto é, a partir de um arquivo (cf. COURTINE, 2014, sobre formas distintas de corpora). Entendemos arquivo num sentido amplo, em consonância com a indicação de Pêcheux em Ler o arquivo boje: "campo de documentos pertinentes e disponíveis sobre uma questão" (PÊCHEUX, 1994, p. 57). Desse arquivo preexistente, constituído pelos artigos do periódico online Horizontes de Linguística Aplicada, foram selecionados artigos que abordam as novas tecnologias no trabalho com línguas estrangeiras (seleção feita a partir de um olhar ao título e ao resumo). Destacamos então sequências discursivas que, como vestígios de processos discursivos, possibilitariam esboçar os contornos de uma formação discursiva que, em sua relação com outras formações, determina tanto o que pode e deve ser dito quanto o que não pode e não deve ser dito acerca das novas tecnologias na teorização sobre o ensino e a aprendizagem de línguas estrangeiras.

$\mathrm{Na}$ análise aqui apresentada, levamos em consideração a oposição traçada por Pêcheux (1988) entre base linguística e processo discursivo. Se todo sistema linguístico, conjunto de estruturas fonológicas, morfológicas e sintáticas, encontrase submetido a leis internas, que constituem o objeto da Linguística, é contudo "sobre a base dessas leis internas que se desenvolvem os processos discursivos, e não enquanto expressão de um puro pensamento, de uma pura atividade cognitiva" (PÊCHEUX, 1988, p. 91, destaque do autor). A materialidade linguística das sequências discursivas constitutivas de nosso corpus, portanto, será abordada em sua condição de "forma material", isto é, "forma que é linguística e histórica" (ORLANDI, 1997, p. 102).

Foi com o intuito de abordar as formas materiais com as quais estivemos às voltas na pesquisa que nos sustentamos na indicação de Pêcheux (1997a) de que as práticas de análise jogam com uma alternância entre descrição e interpretação: "Todo enunciado, toda sequência de enunciados é, pois, linguisticamente descritível como uma série (léxico-sintáticamente determinada) de pontos de deriva possíveis, oferecendo lugar à interpretação" (1997a, p. 53). Tomar a língua como base na qual se desdobram os processos discursivos constitutivos do sentido, ou levar em conta a distinção entre interdiscurso (nível da constituição do discurso) e intradiscurso (nível da linearidade do dizer, o "fio do discurso") implica, segundo pensamos, em proceder por uma alternância entre a descrição da materialidade linguística e a interpretação. 
A esse respeito, vale incluir aqui a afirmação de Pêcheux, no texto Ler o arquivo boje, sobre o que configura um trabalho de leitura de arquivo: "É esta relação entre língua como sistema sintático intrinsecamente passível de jogo, e a discursividade como inscrição de efeitos linguísticos materiais na história, que constitui o nó central de um trabalho de leitura de arquivo" (PÊCHEUX, 1994, p. 63, destaques do autor). É, portanto, na alternância, na articulação entre a descrição da materialidade linguística e a interpretação que aponta para os "efeitos linguísticos materiais na história" que pretendemos analisar o discurso acerca das novas tecnologias nos artigos selecionados do periódico Horizontes de Linguística Aplicada.

\section{ANÁLISE}

\subsection{Tecnologias $x$ novas tecnologias: o pré-construído}

De início, abordemos a apresentação ao volume temático 11, número 1 (2012), do periódico Horizontes de Linguística Aplicada, volume que inclui alguns dos artigos analisados na pesquisa ${ }^{3}$. De acordo com as linhas iniciais da apresentação,

$\mathrm{SD}^{4} 1$

Este volume temático, sobre Tecnologias no Ensino de Línguas, traz oito artigos que apresentam resultados de pesquisas realizadas em contexto nacional e internacional e revisões teóricas nesse eixo temático.

A breve descrição de cada um dos artigos, na apresentação, permite vislumbrar que embora o tema do volume seja Tecnologias no ensino de línguas, todos os artigos abordam questões referentes ao que é corriqueiramente chamado de novas tecnologias: um estado-da-arte no Brasil sobre pesquisas que investigam Computer Assisted Language Learning ${ }^{5}$ (CALL), educação de professores de línguas em CALL, limitações e potencialidades da plataforma Moodle para a formação de professores, orientações para a análise e a elaboração de tarefas pedagógicas em cursos virtuais, uso da ferramenta blog como recurso tecnológico promotor de reflexão crítica do aprendiz em cursos de Letras, as potencialidades dos recursos eletrônicos chat e fotobabble para a produção oral e escrita dos aprendizes, a apropriação da tecnologia empregada na Linguística de Corpus para o ensino da produção textual em língua estrangeira, tais são os temas abordados pelos artigos que compõem o volume temático 11, n. 1, do periódico Horizontes.

3. Embora não houvéssemos inicialmente planejado incluir no material de análise os textos de apresentação das revistas selecionadas, tal inclusão veio a se tornar relevante para a pesquisa no caso do referido volume temático.

4. Sequência discursiva.

5. Aprendizagem de Línguas Mediada por Computador, em português. 
Interessa-nos aqui o deslocamento metafórico entre o termo Tecnologias (sem o adjetivo "novas"), tema do referido volume, e itens como computador, plataforma Moodle, ferramenta blog, ambiente virtual, recursos eletrônicos chat e fotobable e cursos virtuais, itens que remetem especificamente às novas tecnologias da informação e comunicação. Em que se fundamenta tal deslocamento? Por um efeito de pré-construído, isto é, "uma construção anterior, exterior, independente por oposição ao que é construído na enunciação" (COURTINE, 2014, p. 74), as Tecnologias advêm como novas tecnologias. É, portanto, no interdiscurso, aquilo que fala "antes, em outro lugar e independentemente" (PÊCHEUX, 1988, p. 162), que as Tecnologias naturalizam-se como novas tecnologias.

Para que o efeito de pré-construído aqui identificado seja mais claramente delineado, abordemos outra sequência discursiva, extraída de artigo que se propõe a refletir sobre o conceito e as possibilidades da "tecnologia educativa":

\section{SD 2}

O uso que o homem faz de uma determinada tecnologia é o que possibilita mudanças que podem ter impacto em todos os envolvidos. Tal questão é relevante para a construção de um projeto pedagógico tecnológico de qualidade, pois deverá envolver não apenas o professor, mas também a direção, a coordenação, a escola como um todo e, principalmente, o aluno. A tecnologia na sala de aula não deve ser apenas um suporte para facilitar a vida do professor, no sentido de, por exemplo, substituir o quadro por apresentações em Powerpoint.

Tal sequência inclui uma discussão acerca do uso que o bomem faz de uma determinada tecnologia, uso que, de acordo com SD 2, éo que possibilita mudanças. Abordaremos este elemento posteriormente. Por ora, vale destacar em SD 2 a relação metafórica que se estabelece entre tecnologia e Powerpoint, pois a condição da tecnologia como apenas um suporte para facilitar a vida do professor - condição a ser evitada, de acordo com a sequência - refere-se a Powerpoint, e não a quadro; a este último é negado, no intradiscurso de SD 2, um possível estatuto de tecnologia. O efeito de sentido que se produz nessa relação de substituição é o de atribuir à tecnologia na sala de aula algo que seria a ela inerente: sua articulação com o uso de um programa de computador (o Powerpoint), portanto com o que seria uma "inovação tecnológica". Efeito de pré-construído a partir do qual desponta a evidência de que, quando se fala em tecnologia, se sabe do que se fala.

Não é sem relevância lembrar que a tecnologia, em contraponto ao efeito de pré-construído aqui identificado, obviamente não se restringe às tecnologias da informação e comunicação, referindo-se antes, de forma ampla, a "um dispositivo, uma ferramenta ou um intrincado artefato destinado a produzir algo" (SIBILLIA, 2016, p. 13). Freud, em O mal-estar da cultura, refere-se aos recursos e atividades úteis 
aos homens como um dos aspectos da cultura. O psicanalista inclui em sua discussão exemplos como a utilização de instrumentos, o controle do fogo e a construção de habitações, os "primeiros atos de civilização" (FREUD, 1976, p. 109). A partir da indicação de que através da criação de instrumentos úteis "o homem recria seus próprios órgãos" (p. 110), Freud inclui exemplos como o microscópio, por meio do qual o homem supera os seus limites de visibilidade, e o telefone, através do qual pode escutar a distâncias anteriormente supostas como inatingíveis. Passa pela escrita - em sua origem, a voz de uma pessoa ausente, segundo Freud - e referese inclusive aos meios de comunicação, que seriam "amplos, rápidos e dignos de confiança" (p. 112).

Freud remete esses elementos da cultura a um desamparo do homem, e também a um ideal de onipotência e onisciência corporificado em seus deuses. Com tais elementos obtidos através de sua ciência e tecnologia, conta-nos Freud, o homem se tornou uma espécie de "Deus de prótese": "Quando faz uso de todos os seus órgãos auxiliares, ele é verdadeiramente magnífico" (p. 111). Entretanto, o psicanalista afirma que, a despeito de avanços inimagináveis que as épocas futuras provavelmente trarão, e que aumentarão a semelhança do homem com Deus, o homem não se sente feliz em seu papel de semelhante a Deus. Da discussão feita por Freud, interessa-nos a indicação acerca da existência de um ideal de onipotência e onisciência que se forma face a um desamparo do homem na terra, ideal que está na base do desenvolvimento de recursos tecnológicos. E também a indicação de que os esforços do homem para obter felicidade na cultura serão sempre marcados por obstáculos. Tais indicações revestem-se de importância para o trabalho desenvolvido aqui, uma vez que apontam para um elemento estrutural na ordem da cultura: uma falta (de amparo, de felicidade) impossível de erradicar, a despeito do desenvolvimento de recursos tecnológicos, recursos que encarnam um certo ideal de onipotência e onisciência.

A despeito do efeito de pré-construído a partir do qual a tecnologia naturalizase como nova tecnologia, há em nosso material de análise o reconhecimento explícito de que a tecnologia no ensino de línguas não se restringe à utilização das tecnologias da informação e comunicação. É o que podemos vislumbrar nas seguintes sequências discursivas:

\section{SD 3}

A aprendizagem de línguas sempre esteve acompanhada de tecnologias, quer no formato de livros e cassetes, quer computadores e dispositivos móveis, todos esses recursos, a seu tempo, foram tecnologias revolucionárias no processo de ensino-aprendizagem (PAIVA, 2001, CHAPELLE; HEGELHEIMER, 2004; OLIVEIRA, 2013). 
SD 4

De acordo com Linard (1996), tecnologia é um "conjunto de discursos, práticas, valores e efeitos sociais ligados a uma técnica particular num campo particular" (LINARD, 1996, apud BELLONI, 2006, p. 53). Assim, o giz, o quadro negro e o livro são tecnologias, porém antigas. Chaves (1999) ratifica a definição anterior e afirma que a tecnologia se refere a tudo o que foi inventado pelo homem com o objetivo de simplificar o trabalho, e, ao mesmo tempo, aprimorar as relações entre os indivíduos.

Em SD 3, extraída de artigo que discute o potencial de dois aplicativos para o ensino e a aprendizagem de línguas estrangeiras, livros e cassetes são colocados em continuidade com computadores e dispositivos móveis, na medida em que todos esses recursos são tecnologias que acompanharam o ensino de línguas, tecnologias que foram, cada uma a seu tempo, revolucionárias no processo de ensino-aprendizagem. SD 4, proveniente de artigo que discute o conceito e as possibilidades da "tecnologia educativa", coloca em cena um efeito de sentido similar, na medida em que, fundamentada em definições de tecnologia, indica que o giz, o quadro negro e o livro didático são tecnologias. Aqui, o quadro negro ganha estatuto de tecnologia, estatuto que lhe foi negado em SD 2.

A copresença do efeito de pré-construído indicado acima (a partir do qual a tecnologia naturaliza-se como nova tecnologia) e do reconhecimento explícito de que a tecnologia não se restringe às novas tecnologias apresenta-se como uma contradição digna de nota em nosso material de análise. Copresença que nos permite vislumbrar a heterogeneidade que marca o discurso acerca das novas tecnologias na teorização sobre o ensino e a aprendizagem de línguas estrangeiras: livros, cassetes, giz e quadro negro são explicitamente reconhecidos como tecnologias, mas o sutil efeito de préconstruído aqui identificado apaga sua condição de recursos tecnológicos. Como se livros, cassetes, etc. fossem e ao mesmo tempo não fossem tecnologias... Em relação a essa contradição, não é sem importância retomar a indicação de Freud (1976) acerca de uma falta não erradicável na ordem da cultura, em relação à qual todos os recursos tecnológicos estão, num certo sentido, em pé de igualdade.

\subsection{0 discurso do material didático}

Em SD 2, importa ainda destacar o enunciado $O$ uso que o bomem faz de uma determinada tecnologia é o que possibilita mudanças que podem ter impacto em todos os envolvidos. Estamos aqui diante da estrutura X É O QUE Y, em que

\footnotetext{
$\mathrm{X}=\mathrm{O}$ uso que o bomem $\mathrm{faz}$ de uma determinada tecnologia

É O QUE

$\mathrm{Y}=$ possibilita mudanças que podem ter impacto em todos os envolvidos
} 
Em sua análise do discurso comunista endereçado aos cristãos, Courtine (2014) tece considerações sobre a estrutura "É...QUE": X É O QUE Y, e as formas semelhantes É X QUE Y e O QUE Y É X. Das considerações do autor, interessanos o destaque à ambiguidade semântica no funcionamento das frases "É...QUE", ambiguidade que, segundo o autor, previne contra a ilusão de transparência do discurso, como se o discurso "falasse por si próprio", dando através de suas formas linguísticas a chave para sua interpretação. Sobre esta ambiguidade, Courtine indica que as frases "É...que" podem receber uma interpretação contrastiva ("o uso, e não outra coisa / e nada mais, é o que possibilita mudanças"), dêitica ou constativa ("o uso, e eventualmente outras coisas, é o que possibilita mudanças"). Em nossa leitura, o emprego da frase X É O QUE Y em SD 2 aponta para a interpretação contrastiva: o uso da tecnologia - e não outra coisa - é o que possibilita mudanças que podem trazer impacto. Trata-se, em nossa leitura, de enfatizar que, no que se refere a uma tecnologia, é o uso feito pelo homem o elemento decisivo. Resta, entretanto, perguntar: qual seria o elemento que, em contraste com o uso de uma tecnologia, não possibilitaria mudanças? A resposta, encontramo-la no mesmo texto, algumas páginas adiante:

SD 5

As tecnologias, por si, não são responsáveis por mudanças drásticas na sociedade. $\mathrm{O}$ uso que fazemos delas é que é capaz de provocar tais mudanças.

Nesta sequência, situada no contexto de uma discussão sobre as tecnologias da informação e comunicação, o termo tecnologias comparece sem outros qualificadores. A partir de uma atenção ao entorno textual, entende-se que se trata das novas tecnologias, porém não deve ficar descartado o fato de que, mais uma vez, por um efeito de pré-construído, a tecnologia desponta como nova tecnologia, com a consequência mencionada acima: como se as tecnologias "antigas" fossem tecnologias, mas ao mesmo não fossem.

Interessa indicar em SD 5 a presença, mais uma vez, da estrutura X É O QUE Y, em que

$$
\begin{aligned}
& \mathrm{X}=\mathrm{O} \text { uso que fazemos delas [das tecnologias] } \\
& \text { É (O) QUE } \\
& \mathrm{Y}=\text { é capaz de provocar tais mudanças [drásticas] }
\end{aligned}
$$

Em SD 5, um efeito contrastivo se faz presente novamente: é o uso que se faz das tecnologias - e não as tecnologias por si - que é capaz de provocar mudanças. $\mathrm{O}$ contraste se estabelece entre uso das tecnologias e a tecnologia em si, dessa vez com 
a presença do advérbio não (as tecnologias, por si, não são responsáveis por mudanças drásticas) no intradiscurso de SD 5, dando-se assim destaque ao uso que é feito da tecnologia em detrimento das tecnologias em si mesmas. No artigo do qual extraímos SD 2 e SD 5, encontramos ainda outras frases do tipo "É...QUE", em que se vislumbra o mesmo efeito contrastivo. Vejamos SD 6:

SD 6

Menezes (2003) sugere que é a própria tecnologia que guia e direciona todas as mudanças na sociedade. Essa idéia carece de ressalvas, haja vista que é o uso que se faz da tecnologia o grande responsável pelas mudanças, ou seja, é o homem quem gerencia as mudanças que a tecnologia é capaz de propiciar

SD 6 situa-se no contexto de uma discussão acerca das novas tecnologias, mas o termo tecnologia comparece novamente sem qualificadores; vislumbra-se aqui o efeito de pré-construído mencionado acima. Nesta sequência, retoma-se a sugestão de uma autora (Menezes) segundo a qual é a própria tecnologia que guia e direciona todas as mudanças na sociedade. A tal afirmação, contrapõem-se: a) a afirmação segundo a qual é o uso que se faz da tecnologia o grande responsável pelas mudanças; b) a frase (de tipo "É... que") é o bomem quem gerencia as mudanças que a tecnologia é capaz de propiciar. Poderíamos parafrasear, de modo a explicitar o efeito contrastivo que se depreende de SD6: É o uso que o bomem faz da tecnologia que é capaz de propiciar mudanças, não a própria tecnologia.

$\mathrm{Na}$ próxima sequência, extraída de artigo que discute as fases da pesquisa sobre aprendizagem de línguas mediada por computador (CALL) no Brasil, podemos também vislumbrar a presença da estrutura "É...QUE":

\section{SD 7}

Para a autora, embora "os recursos técnicos ofereçam muitas possibilidades" para a implementação de novas alternativas para os processos de ensino e de aprendizagem de línguas, "não é o meio (eletrônico) que é definidor, mas o uso que fazemos dele é que pode viabilizar mudanças pedagógicas" (idem, p. 185)

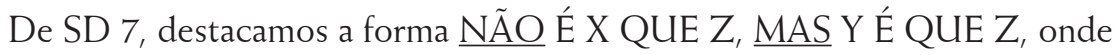

$$
\begin{gathered}
\mathrm{X}=\text { o meio eletrônico } \\
\mathrm{Y}=\text { o uso que fazemos do meio eletrônico } \\
\mathrm{Z}=\text { é definidor / pode viabilizar mudanças pedagógicas }
\end{gathered}
$$

Nota-se também, em SD 7, a presença da conjunção adversativa mas, que ao lado do advérbio não contribui para o contraste estabelecido entre, por um lado, o meio eletrônico (em si) e, por outro, o uso que fazemos dele, este sim definidor, e podendo viabilizar mudanças pedagógicas. 
O efeito contrastivo que identificamos em nossa análise, e que pode ser vislumbrado nas frases de tipo "É...que" de nosso corpus, nos permite abordar um elemento importante no discurso acerca das novas tecnologias na teorização sobre o ensino e a aprendizagem de línguas estrangeiras, pelo menos no âmbito do material analisado aqui: a tentativa de banir de seu interior, rechaçar a tecnologia em si, colocando ênfase no "uso que se faz da tecnologia". Seria tal tentativa bem sucedida? Retomaremos esse ponto adiante.

No que se refere à ênfase no uso que se faz das tecnologias, talvez não seja sem relevância retomar o que, no âmbito da Linguística Aplicada, chamaremos de discurso do material didático. Um elemento que, em nossa leitura, é essencial neste discurso é a definição de material didático fornecida por Tomlinson (1999) no livro Materials development in language teaching, um clássico da área, definição de acordo com a qual material didático se refere a "qualquer coisa que é utilizada por professores e aprendizes para facilitar a aprendizagem de uma língua" (p. 2, tradução minha ${ }^{6}$, ou ainda "qualquer coisa que é deliberadamente utilizada para incrementar o conhecimento e/ou experiência da língua" (p. 2)7. Nas definições fornecidas pelo autor, importa destacar a existência de dois elementos distintos, quais sejam, o material didático em si ("qualquer coisa") e a sua "utilização". A esse respeito, importa também retomar a discussão feita por Bell e Gower (1999), no livro Materials development in language teaching, sobre livros didáticos internacionais em aulas de língua estrangeira. Discutindo os prós e contras da utilização de tais materiais, os autores fazem uma afirmação digna de nota: "Tudo depende da relação que um usuário, em particular um professor, tem ou pode ter com o material. Livros didáticos são ferramentas que apenas possuem vida e significado quando há um professor presente" (p. 118, tradução minha ${ }^{8}$ ). Para além da discussão mais específica sobre o livro didático, vale destacar da afirmação dos autores a indicação de que, no que se refere a materiais didáticos, tudo depende da relação que um usuário estabelece com o material. Acreditamos que o discurso acerca das novas tecnologias na teorização sobre o ensino e a aprendizagem de línguas estrangeiras sofre os efeitos do discurso do material didático, a partir do qual se faz uma distinção entre o material em si e o seu uso, com ênfase no segundo elemento, em detrimento do primeiro. Interessa indicar, a esse respeito, que embora as tecnologias de informação e comunicação

6. Em inglês: "anything which is used by teachers or learners to facilitate the learning of a language".

7. Em inglês: "anything which is deliberately used to increase the learners' knowledge and/or experience of the language".

8. Em inglês: "It all depends on the relationship that a user, in particular a teacher, has or is allowed to have with the material. Coursebooks are tools which only have life and meaning when there is a teacher present". 
sejam consideradas "novas", elas se inserem no já (há muito tempo!) dito acerca dos materiais didáticos como instrumentos utilizados para contribuir com o ensino e a aprendizagem de línguas estrangeiras.

Sobre a perspectiva instrumental colocada em cena no discurso do material didático, discurso que parece exercer seus efeitos nos artigos analisados, interessa incluir a seguinte sequência discursiva:

\section{SD 8}

Segundo Miranda (2007), as NTIC são redundantes. Para ela, "a referência à novidade nada acrescenta à delimitação e clarificação do domínio. Mais ainda, o que é novo hoje deixa de o ser amanhã" (MIRANDA, 2007, p. 43). Assim, dois aspectos são relevantes: (1) as "novas" tecnologias nem sempre chegam para substituir as "velhas", mas podem ser utilizadas juntas para tentar resolver problemas, como, por exemplo, contribuir para o processo de ensino e aprendizagem, (2) as NTIC já estão postas e nos resta refletir sobre as melhores e mais adequadas maneiras de utilizá-las, principalmente os professores que trabalham com as crianças e jovens nascidos na era digital.

De SD 8, extraída de texto que discute a "tecnologia educativa", importa destacar a indicação de que, de acordo com um autor citado (Miranda), a referência à novidade nada acrescenta à delimitação e clarificação das tecnologias de informação e comunicação, e também a afirmação do mesmo autor segundo a qual o que é novo boje deixa de o ser amanhã. Ainda nessa direção, interessa destacar a afirmação de que as "novas" tecnologias nem sempre chegam para substituir as "velhas", na qual os adjetivos novas e velhas comparecem entre aspas, recurso que interpretamos como uma tentativa de relativizar a qualificação das tecnologias de acordo com sua "novidade" ou "antiguidade". Em contraponto ao efeito de pré-construído identificado anteriormente nos artigos analisados, a partir do qual a tecnologia desponta como nova tecnologia, com o apagamento do estatuto de tecnologia dos recursos "antigos", SD 8 parece estabelecer uma continuidade entre as tecnologias "velhas" e "novas". O ponto importante a destacar aqui é que o estabelecimento de tal continuidade se sustenta, em SD 8, na perspectiva instrumental do discurso do material didático: as "novas" tecnologias nem sempre chegam para substituir as "velhas", mas podem ser utilizadas juntas para tentar resolver problemas, como, por exemplo, contribuir para o processo de ensino e aprendizagem. Como indicamos acima, a copresença do efeito de pré-construído aqui mencionado e do estabelecimento de uma continuidade entre "velhas" e "novas" tecnologias no caso específico de SD 8, continuidade que se sustenta no discurso do material didático - dá mostras da heterogeneidade que marca o discurso acerca das novas tecnologias na teorização sobre o ensino e a aprendizagem de línguas estrangeiras.

Entretanto, no que se refere às tecnologias da informação e comunicação, e levando-se em conta sua presença maciça em âmbitos os mais variados das relações 
sociais contemporâneas, seria a perspectiva instrumental suficiente, a partir da qual as novas tecnologias despontam como ferramentas neutras? Sibillia (2016), em sua discussão sobre a informatização das escolas, traz uma contribuição fundamental a esse respeito:

Pois a tão buscada adequação entre escola e o mundo atual não deve limitar-se a "usar as tecnologias como recursos didáticos", ou a "fazer da telemática um instrumento a favor do barateamento e da disseminação do ensino", como alerta Alfredo Veiga Neto. Esse tipo de reducionismo é bastante habitual e costuma revelar um apego àquilo que muitos consideram a "velha e boa escola moderna", segundo a expressão do mesmo autor. Em tais casos, a aparelhagem técnica é considerada um mero instrumento a ser incorporado às práticas escolares, como se fosse uma ferramenta neutra capaz de atualizá-las, remediando assim a tão proclamada crise. É evidente que essas adaptações também são necessárias e até promissoras, mas seria ingênuo acreditar que solucionariam por si sós os complicados problemas que foram discutidos ao longo deste ensaio. Com efeito, nem os computadores nem a internet nem os telefones celulares são recursos "neutros", como se costuma dizer, cuja eficácia dependeria da utilização que lhes é dada. Ao contrário, como ocorre com todas as máquinas, essas não são boas nem más, porém tampouco se pode supor que sejam neutras. Carregam consigo uma série de valores e modos de uso que estão implícitos, por mais que sempre exista certo grau de flexibilidade, agenciamento, experimentação e apropriação por parte de seus usuários, mas isso não significa que não possuam sua própria materialidade e sua marca bastante precisa. (SIBILLIA, 2016, p. $181-182$, destaque meu)

As elaborações de Sibillia possibilitam formular a seguinte pergunta: para além da perspectiva de uma neutralidade das novas tecnologias como instrumentos a serem utilizados por professores e alunos, neutralidade que se constitui na referência ao que nomeamos de discurso do material didático, qual seria a materialidade própria aos computadores e dispositivos conectados à internet? Qual seria sua marca precisa? Eis o ponto central a ser abordado. O que está em cena quando se "usa" as novas tecnologias hoje?

\subsection{A promessa}

Para que prossigamos, abordemos mais uma sequência discursiva:

\section{SD 9}

Por pertencer a uma era transformada pelas novas tecnologias, o aluno de hoje necessita de uma escola que atenda suas necessidades. O professor, que tem assumido um papel controlador na administração da dinâmica da aula, assumirá outras funções, tais como orientar os alunos no seu processo de aprendizagem que, agora, será complementado por recursos tecnológicos. Dentre outras inovações, esses recursos permitirão que os alunos frequentem ambientes virtuais, onde terão autonomia em sua experiência de aprendizagem (MARTINS, 2005).

Nesta sequência, as novas tecnologias comparecem como recursos que permitirão que os alunos frequentem ambientes virtuais. Possibilitar que os alunos assim o façam é 
configurado, em SD 9, como uma "inovação", o que aponta para um elemento importante nos artigos analisados na pesquisa: um ideal de inovação articulado às novas tecnologias. Se por um lado tal ideal de inovação comparece também, em nosso material de análise, como elemento que não está necessariamente articulado às inovações tecnológicas, encontrando-se na dependência de um certo fazer pedagógico, a inovação como um ideal a ser atingido a partir do uso das novas tecnologias é elemento que se faz presente nos artigos sobre os quais nos detivemos.

Contudo, o ponto que gostaríamos de destacar em SD 9 é que tal sequência coloca em cena uma espécie de promessa: nos ambientes virtuais, os alunos terão autonomia em sua experiência de aprendizagem, promessa na qual os ambientes virtuais despontam como garantia de autonomia do aluno. De forma a explorar esse ponto, abordemos outra sequência discursiva, extraída de artigo sobre a aprendizagem de línguas in-tandem:

\section{SD 10}

As novas tecnologias vêm sendo utilizadas como recursos de aprendizagem e têm ocasionado mudanças significativas nas mais diversas áreas da educação, como, por exemplo, no ensino de língua estrangeira. Dentre essas tecnologias, o computador e a Internet destacam-se, pois tornam o ensino mais atrativo e inovador, inserindo alunos e professores no mundo globalizado (PAIS, 2005).

De início, vislumbra-se aqui a mencionada articulação entre novas tecnologias e inovação: o computador e a Internet comparecem, em SD 10, como elementos que possibilitam um ensino inovador. Trata-se, portanto, da projeção de um ideal de inovação que o computador e a internet permitiriam atingir. Contudo, o ponto que desejamos destacar aqui refere-se à configuração das novas tecnologias como promessa. De acordo com a sequência, o computador e a Internet tornam o ensino mais atrativo e inovador, inserindo alunos e professores no mundo globalizado. Aqui, as figuras do professor e do aluno tornam-se objeto de uma ação realizada pelo computador e a Internet, que são portanto configurados como possuidores de um valor em si.

Talvez não seja sem relevância recorrer à argumentação de Bax (2003) sobre as falácias que afetam a percepção de alunos, professores e administradores acerca das novas tecnologias. Uma delas é nomeada por Bax de "falácia do agente único", e caracteriza-se pela "suposição corriqueira de que o fator chave, ou o único fator, na implementação da tecnologia é a tecnologia em si - o que poderíamos chamar de falácia do 'Agente Único'" (BAX, 2003, p. 26, tradução minha ${ }^{9}$ ). Em SD 10, portanto, a falácia é a de que o computador e a internet seriam garantia de um ensino mais atrativo e inovador, independente da participação de professores e alunos no

9. Em inglês: "common assumption that the key or only factor in successful implementation of the technology is the technology itself - what we could call the 'Sole Agent' fallacy". 
processo. Para continuar explorando esse ponto, abordemos mais uma sequência discursiva:

\section{SD 11}

As novas tecnologias vêm sendo utilizadas como suporte ao processo de aprendizagem e têm produzido mudanças em diferentes contextos educacionais, principalmente, na área de ensino de línguas estrangeiras (PAIS, 2005). Dentre essas mudanças, destaca-se a utilização de computadores e internet no Ensino Público, que possibilita aos alunos novas formas de comunicação com o mundo e, consequentemente, com falantes nativos e outros aprendizes da língua estrangeira ensinada na escola (ALMEIDA; FONSECA JUNIOR, 2000). O emprego dessas ferramentas tecnológicas visa à inovação do ensino, tornando-o mais envolvente e produtivo: "a informática trará novas possibilidades, resultando em uma aprendizagem mais eficiente, mais profunda, mais confortável, mais feliz." (p. 67)

Em SD 11, extraída do mesmo artigo que a sequência anterior, há novamente a configuração de um ideal de inovação do ensino, a ser atingido através do emprego [de] ferramentas tecnológicas. Tal ideal de inovação, em nossa leitura, materializa-se também na menção, em SD 11, às novas possibilidades que a informática trará, e às novas formas de comunicação com o mundo que a utilização de computadores e internet no Ensino Público [...] possibilita. O ponto fundamental a ser destacado, contudo, refere-se à afirmação de que a informática trará novas possibilidades, resultando em uma aprendizagem mais eficiente, mais profunda, mais confortável, mais feliz. Promessa de eficácia, profundidade, conforto e felicidade que exclui qualquer participação de alunos e professores no processo de aprendizagem.

Retomando a argumentação de Bax (2003), pode-se dizer que a falácia se concretiza, nas duas sequências anteriormente abordadas, na promessa de um ganho "a mais" no ensino e na aprendizagem: promessa de um ensino mais atrativo e inovador (SD 10) e de uma aprendizagem mais eficiente, mais profunda, mais confortável, mais feliz (SD 11). À promessa de um ganho "a mais", vislumbrada em conexão com o computador e a Internet (SD 10) e a informática (SD 11), junta-se a promessa de autonomia na experiência de aprendizagem, supostamente garantida pelos ambientes virtuais (SD 9). Tais promessas, nas quais as novas tecnologias comparecem como uma espécie de garantia, não deixam de retirar de professores e alunos a condição de protagonistas da cena pedagógica, configurando-os como elementos secundários no processo de ensino e aprendizagem.

A análise aqui apresentada apontou a presença - conferir, a esse respeito, SD's 2, 5, 6 e 7 - da estrutura "É...QUE", com suas variantes X É O QUE Y, É X QUE Y e O QUE Y É X (cf. COURINTE, 2014). Apontamos então para a presença de um efeito contrastivo em nosso material de análise, a partir do qual é o uso que se faz das novas tecnologias - e não as novas tecnologias em si - que faz 
a diferença, que pode viabilizar mudanças pedagógicas. Indicamos então que o discurso acerca das novas tecnologias na teorização sobre o ensino e a aprendizagem de línguas, pelo menos a nos valermos de nossa análise, é constituído por uma tentativa de banir de seu interior, rechaçar a tecnologia em si, colocando ênfase no uso que se faz da tecnologia, em conformidade com os efeitos de sentido do que chamamos de discurso do material didático. Ora, a falácia (cf. BAX, 2003) que vislumbramos em nosso material de análise, segundo a qual os ambientes virtuais (SD 9), o computador e a Internet (SD 10) e a informática (SD 11) despontam como garantias em si, parece indicar que, a despeito da tentativa de excluir a tecnologia em si para fora de seu domínio, o discurso cujo contorno desejamos delinear não deixa de ser afetado pelo elemento do qual tentou se desvencilhar. Contudo, se a formação discursiva que informa os dizeres sobre as novas tecnologias nos artigos analisados é afetada/ constituída pelo que lhe é exterior, esse "de fora" é também discurso. Discurso que, embora negado, insiste em se fazer presente na materialidade linguística dos artigos analisados na pesquisa. A nos guiarmos pela análise aqui apresentada, somos levados a supor que, no jogo interdiscursivo que constitui o discurso acerca das novas tecnologias na teorização sobre o ensino e a aprendizagem de línguas, há vestígios do que chamaremos de discurso da tecnologia em si, em consonância com o que Bax (2003) chama de falácia do agente único: a "suposição corriqueira de que o fator chave, ou o único fator, na implementação da tecnologia é a tecnologia em si" (BAX, 2003, p. 26, tradução minha $\left.{ }^{10}\right)$. Nas SD’s 9, 10 e 11, é na forma da falácia que o discurso da tecnologia em si, banido no confronto com o discurso do material didático, faz o seu retorno.

Portanto, o discurso da tecnologia em si encontra-se, no que se refere à formação discursiva que buscamos delinear na pesquisa, "fora-dentro": "banido" em função da presença dos efeitos de sentido do discurso do material didático, o discurso da tecnologia em si não deixa de se fazer presente na formação discursiva que configura os sentidos de novas tecnologias na teorização sobre o ensino e a aprendizagem de línguas estrangeiras. Neste ponto, talvez valha a pena retomar a indicação de Courtine (2014) de acordo com a qual o fechamento de uma formação discursiva é fundamentalmente instável: "não consiste num limite traçado, de uma vez por todas, mas se inscreve entre diversas FD como uma fronteira que se desloca, em razão dos jogos da luta ideológica, nas transformações da conjuntura histórica de uma dada formação social" (p. 99-100, destaque do autor).

10. Em inglês: "common assumption that the key or only factor in successful implementation of the technology is the technology itself". 


\subsection{Subjetivação, poder, silenciamento}

Em conformidade com os efeitos de sentido do discurso do material didático, as novas tecnologias comparecem, no âmbito da teorização, como um instrumento, uma ferramenta que está na dependência da forma pela qual é utilizada por professores e alunos na cena pedagógica. Perguntamo-nos anteriormente se considerar as novas tecnologias como ferramentas neutras, à disposição da forma de uso por professores e alunos, seria suficiente hoje, dada sua presença maciça em espaços os mais variados da vida social. Trouxemos, então, a indicação de Sibillia (2016) de que embora haja algum grau de flexibilidade e apropriação por parte dos usuários das novas tecnologias, isso não quer dizer que elas sejam neutras, que não possuam uma materialidade própria e uma marca precisa - contraponto importante ao que nomeamos de discurso do material didático. Formulamos então uma questão: qual seria a materialidade própria aos computadores e dispositivos conectados à internet? Qual seria sua marca precisa?

Segundo Sibillia (2016), os dispositivos eletrônicos com que se convive hoje, utilizados para realizar as mais diversas tarefas, desempenham um papel vital nas transformações que caracterizam o mundo contemporâneo. Tal utilização, segundo Sibillia, pode ser vista como uma estratégia para que os sujeitos se mantenham à altura de "novas coações culturais" (p. 51), coações que engendram "maneiras inéditas de ser e estar no mundo" (p. 51). A partir das indicações de Sibillia, podese dizer que o uso das inovações tecnológicas, seja no âmbito educacional ou não, articula-se a novas formas de subjetivação na sociedade contemporânea. $\mathrm{O}$ problema com o discurso do material didático, a partir do qual as novas tecnologias despontam como ferramentas neutras à disposição de professores e alunos, é que nessa perspectiva se elide, justamente, o ponto em que o "usuário" das novas tecnologias é, por elas, subjetivado.

Em sua discussão, Sibillia (2016) indica que as maneiras inéditas de ser e estar no mundo hoje, marcadas pelo uso das novas tecnologias, articulam-se estreitamente a toda uma engrenagem de poder e controle. Segundo a autora, os modos de ser e estar no mundo contemporâneo se sustentam numa constante exposição interativa, sendo orientados para um olhar alheio. Pode-se pensar, a esse respeito, num tipo de controle "baseado na visibilidade minuciosa, total e permanente" (ALFREDO VEIGA NETO apud SIBILLIA, 2016, p. 168). Trata-se de um controle "permanente, horizontal e minucioso" (p. 169), como afirma Sibillia: "Na sociedade de controle todos controlam todos, todos vigiam todos, durante todo o tempo e em qualquer lugar" (ALFREDO VEIGA NETO apud SIBILLIA, 2016, p. 169). Segundo Sibillia, tal controle "dissemina-se por todos os espaços, sem limites temporais" ( $\mathrm{p}$. 
172). O ponto fundamental, contudo, é que trata-se de um controle, de um olhar, "fervorosamente desejado e buscado" (p. 169). Sibillia continua:

Assim, em vez da prisão - com suas grades, seus cadeados, suas normas estritas e punições
severas -, teríamos como modelo universal, cada vez mais, uma rede eletrônica aberta e sem
fios, a qual cada um se conecta por livre espontânea vontade: apenas onde, quando e se
quiser. Por isso, ali onde imperavam as normas ríspidas do confinamento para educar os cidadãos
oitocentistas com a força do sangue, do suor e da palavra, agora se estendem as tramas atraentes
da conexão, que opera de outro modo e com objetivos diferentes: enfeitiçando os consumidores
contemporâneos com suas incontáveis delícias transmidiáticas. (SIBILLIA, 2016, p. 174-175).

Sibillia refere-se ao desejo de relatar - de modo constante e voluntário os usos mais banais do tempo e do espaço. Tudo isso realizado a toda hora por milhões de pessoas, às quais não incomoda o fato de estarem sempre localizáveis e disponíveis para contato. Segundo a autora, esse meticuloso trabalho individual agora realizado, e que não deve ter pausa, não é empreendido em obediência à pesada obrigação moral de cumprir regulamentos e evitar castigos, como ocorria sob a lógica do confinamento disciplinar, afirma a autora. Ao contrário, tudo isso hoje se faz por prazer, e desperta o interesse dos demais. Vale retomar, a esse respeito, as indicações de Safatle (apud KEHL, 2015) e Kehl (2015) acerca das sociedades contemporâneas, que ao invés de se basearem numa renúncia ao gozo, sustentam-se numa injunção constante ao mesmo. Uma injunção, a nos valermos da discussão feita por Sibillia, às "incontáveis delícias transmidiáticas" que "enfeitiçam os consumidores".

Configura-se, portanto, "uma rede muito eficaz de permanente controle mútuo" (SIBILLIA, 2016, p 175), segundo Sibillia. Pois estamos, de acordo com a autora, "livremente" conectados às redes sociais, e também ao correio eletrônico, ao telefone celular, aos sistemas de localização GPS, aos cartões de crédito... E estas práticas são exercidas "com devoção cotidiana, o tempo todo, porque queremos e porque isso nos agrada" (p. 177). Estamos, pois, às voltas com um poder sutil e, portanto, mais difícil de mapear e burlar.

A discussão aqui realizada permite entrever um elemento importante da materialidade própria aos computadores e dispositivos conectados à internet, isto é, o que pode estar em cena quando se trata de "usar" as novas tecnologias hoje. Vislumbra-se assim um mecanismo de controle que ultrapassa o "usuário" das inovações tecnológicas. O discurso do material didático, a partir do qual as novas tecnologias despontam como ferramentas neutras à disposição de professores e alunos, elide o ponto em que o uso das inovações tecnológicas, seja no âmbito educacional ou não, vincula-se a toda uma engrenagem de poder e controle na sociedade contemporânea. Eis, em nossa leitura, o que há de radicalmente novo no 
que se refere às inovações tecnológicas, e que fica silenciado no discurso acerca das novas tecnologias na teorização sobre o ensino e a aprendizagem de línguas.

\section{CONSIDERAÇÕES FINAIS}

Uma tecnologia corresponde, de forma ampla, a "um dispositivo, uma ferramenta ou um intrincado artefato destinado a produzir algo" (SIBILLIA, 2016, p. 13), não se restringindo, obviamente, a uma tecnologia da informação e comunicação. A esse respeito, há nos artigos analisados o reconhecimento explícito de que o livro, o quadro negro, o giz, etc. são também recursos tecnológicos utilizados no trabalho com línguas estrangeiras. Contudo, ao lado de tal reconhecimento há um efeito de pré-construído que, sutilmente, nega a tais recursos o estatuto de tecnologia, efeito a partir do qual a tecnologia advém como nova tecnologia. Eis, portanto, a primeira marca de uma heterogeneidade contraditória na formação discursiva que nos propusemos a abordar, heterogeneidade a partir da qual o livro, o quadro negro e o giz são e, ao mesmo tempo, não são recursos tecnológicos. Em nossa leitura, o efeito é o de uma valorização das novas tecnologias em detrimento das "antigas", como se as inovações tecnológicas fossem feitas de um estofo à parte, e revelassem o que a tecnologia é "de fato". As elaborações sobre a tecnologia feitas por Freud em $\mathrm{O}$ mal-estar na cultura nos auxiliaram na medida em que, no que se refere aos recursos tecnológicos, remetem a um elemento estrutural em relação a qual todos os recursos estão, num certo sentido, em condições iguais: uma falta (de amparo, de felicidade) não eliminável na ordem da cultura e, face a isso, a projeção de um ideal de onipotência e onisciência que está na base do desenvolvimento de tecnologias. As tecnologias da informação e comunicação, nesse sentido, são como as "antigas".

Foi também possível vislumbrar que o discurso do material didático não deixa de se contrapor ao referido efeito de pré-construído. Em contraponto ao destaque dado às novas tecnologias em detrimento das "antigas", tal discurso configura uma perspectiva instrumental na qual as novas tecnologias, assim como as "antigas", estão na dependência da forma pela qual são utilizadas por professores e alunos. $\mathrm{O}$ discurso do material didático coloca em pé de igualdade todos os recursos didáticos, contrapondo-se à valorização das novas tecnologias que vislumbramos no material analisado.

A análise aqui apresentada aponta para a existência de efeitos de sentido que se produzem na relação entre o discurso do material didático e o discurso da tecnologia em si. No jogo interdiscursivo aqui delineado, é antes de tudo uma relação de embate que se estabelece entre os dois discursos. A análise abordou 
frases do tipo "É...QUE", que colocam em cena um efeito contrastivo a partir do qual é o uso que se faz das novas tecnologias - e não as novas tecnologias em si - que faz a diferença, que pode viabilizar mudanças pedagógicas. Tal efeito indica que o discurso acerca das novas tecnologias na teorização sobre o ensino e a aprendizagem de línguas estrangeiras é constituído por uma tentativa de banir de seu interior, rechaçar a tecnologia em si, dando destaque ao uso que se faz da tecnologia, em conformidade com os efeitos de sentido do discurso do material didático. Embora afetados por uma tentativa de exclusão, os efeitos de sentido produzidos no âmbito do discurso da tecnologia em si não deixam de retornar e exercer efeitos sobre a construção discursiva das novas tecnologias. Nosso material de análise não deixa de ser afetado pela falácia, sobre a qual nos fala Bax (2003), segundo a qual o único fator, ou o fator principal, na implementação da tecnologia é a tecnologia em si. Tal falácia se faz presente, no material analisado, na forma de uma configuração das novas tecnologias como uma garantia de autonomia, eficácia e felicidade no ensino e na aprendizagem de línguas estrangeiras.

Por um lado, o discurso do material didático não deixa de se contrapor ao efeito de pré-construído identificado na análise, a partir do qual as tecnologias "antigas" têm o seu estatuto de tecnologia elidido. Por outro lado, tal discurso, ao enfatizar a questão do "uso", da "utilização" do recurso, elide justamente o ponto em que as novas tecnologias nos subjetivam: para além de serem ferramentas neutras utilizadas pelos participantes da cena pedagógica, elas são parte integrante de "maneiras inéditas de ser e estar no mundo" (SIBILLIA, 2016, p. 51) engendradas por "novas coações culturais" (SIBILLIA, 2016, p. 51) no mundo contemporâneo. Tal ponto de subjetivação, elidido pelo discurso do material didático, articula-se ao exercício de um poder sutil, mais difícil de burlar, poder que se exerce, a nos guiarmos pelas elaborações de Sibillia (2016), não em função da obediência à obrigação moral de cumprir regulamentos e evitar castigos, mas porque isso nos agrada. Vivemos hoje no contexto de uma constante injunção ao prazer e à felicidade. Ou, como indicam Safatle (apud KEHL, 2015) e Kehl (2015), numa sociedade que se sustenta numa injunção constante ao gozo. Eis, parece-nos, o que há de radicalmente novo no que se refere às novas tecnologias: sua articulação a uma nova configuração libidinal no âmbito social.

A análise aqui apresentada não deve ser lida como uma crítica aos artigos do periódico Horizontes de Linguística Aplicada aqui abordados, embora saibamos que não se pode controlar ou prever os efeitos de um texto sobre seus leitores. Não se tratou aqui, tampouco, de qualquer apreciação negativa referente à utilização das novas tecnologias no trabalho com línguas estrangeiras, justamente porque nos 
abstivemos de uma discussão sobre o valor pedagógico que tais dispositivos podem, de fato, assumir. $\mathrm{O}$ que pretendemos fazer aqui foi ler uma pequena parte do arquivo constituído pelos artigos do periódico online Horizontes de Linguística Aplicada, de modo a tentar vislumbrar as relações interdiscursivas que constituem o discurso acerca das novas tecnologias na teorização sobre o ensino e a aprendizagem de línguas estrangeiras. Tentamos apenas, em consonância com a indicação de Pêcheux sobre o que configura o "nó central" de um trabalho de leitura de arquivo, abordar a "inscrição de efeitos linguísticos materiais na história" (PÊCHEUX, 1994, p. 63) engendrada pelos artigos analisados em sua condição de discurso.

\section{REFERÊNCIAS}

ALTHUSSER, L. (1970). Aparelhos Ideológicos de Estado, trad. Walter José Evangelista e Maria Laura Viveiros de Casto. Rio de Janeiro: Edições Graal, 1998.

BAX, S. (2003). CALL - past, present and future. System - an international journal of Educational Technology and Applied Linguistics, v. 31, pp. 13-28.

BELL, J; GOWER, R. (1998). Writing course materials for the world: a great compromise. In: TOMLINSON, B. (org.), Materials development in language teaching. Cambridge: Cambridge University Press, 1999, pp. 116-129.

BENVENISTE, E. (1966). Problemas de Linguística Geral I, trad. Maria da Glória Novak e Maria Luisa Neri. Campinas: Pontes, 2005.

COURTINE, J. J. (2009). Análise do discurso político - O discurso comunista endereçado aos cristãos, trad. Cristina de Campos Velho Birck et al. São Carlos: EDUFSCAR, 2014.

CUNHA, M. C. K.; SOUZA, A. G. (2009). Reflexões sobre a tecnologia educativa. Horizontes de Linguística Aplicada, v. 8, nº1, pp. 82-99.

FREUD, S. (1929). O mal-estar na civilização. Edição Standard Brasileira das Obras Psicológicas Completas de Sigmund Freud. Trad. José Octávio de Aguiar Abreu. Rio de Janeiro: Imago, 1976, v. XXI.

KEHL, M. R, BUCCI, E. (2004). Videologias. São Paulo: Boitempo, 2015.

LACAN, J. (1953-1954). O Seminário, livro 1, Os escritos técnicos de Freud, trad. Betty Milan. Rio de Janeiro: Jorge Zahar Ed., 1986. 
ORLANDI, E. (1996). A linguagem e seu funcionamento - As formas do discurso. Campinas: Pontes, 1996.

ORLANDI, E. (1997). As formas do silêncio - No movimento dos sentidos. Campinas: Editora da UNICAMP, 1997.

PÊCHEUX, M. (1969). Análise Automática do Discurso. In: GADET, F. e T. HAK (orgs.), Por uma análise automática do discurso - Uma introdução à obra de Michel Pêcheux. Campinas: Editora da UNICAMP, 1997, pp. 61-161.

PÊCHEUX, M. (1982). Ler o arquivo hoje. In: ORLANDI, E. (org.), Gestos de leitura - da história no discurso. Campinas: Editora da UNICAMP, 1994, pp. 55-64.

PÊCHEUX, M. (1983). O Discurso: estrutura ou acontecimento. Campinas: Pontes, 1997a.

PÊCHEUX, M. (1975). Semântica e Discurso - Uma crítica à afirmação do óbvio, trad. Eni Pulcinelli Orlandi et al. Campinas: Editora da UNICAMP, 1988.

PÊCHEUX, M., HAROCHE, C. e HENRY, P. (1971). La sémantique et la coupure saussurienne: langue, langage, discours. In: MALDIDIER, D. L'inquietude du discours. Paris: Editions de Cendres, 1990, pp.133-153.

SIBILLIA, P. (2012). Redes ou paredes - A escola em tempos de dispersão, trad. Vera Ribeiro. Rio de Janeiro: Contraponto, 2016.

TOMLINSON, B. (1998). Introduction. In: TOMLINSON, B. (org.) Materials development in language teaching. Cambridge: Cambridge University Press, 1999, pp. 1-24.

Recebido: 24/01/2019

Aceito: 6/05/2019

Publicado: 6/06/2019 